\title{
Ecología, Espiritualidad, Conocimiento: Una Nueva Utopía Recorre el Mundo
}

\author{
Víctor M. Toledo'
}

¿Bajo qué fórmula secreta 200 mil hogares japoneses logran garantizarse un abasto directo de alimentos sanos provenientes de productores orgánicos? ¿Por qué Cuba, la roja, se está volviendo verde? ¿Qué hizo posible que en el país más extenso del mundo, los indígenas inuit se volvieran los legítimos dueños de la quinta parte del territorio canadiense? ¿Cómo surgieron 130 mil fincas de agricultura orgánica en Europa? ¿Por qué poetas como Octavio Paz, multimillonarios como Douglas Tompkins, teólogos como Leonardo Boff, políticos como Misael Gorvachov, o artistas como Maurice Béjart, reconocieron en la defensa del planeta la empresa suprema? ¿Por qué los campesinos de Centroamérica - los «sin tierra» de Brasil se están volviendo militantes de la agroecología?¿Alguien logró anticipar lo que hoy hacen unas 2 mil comunidades rurales en México, artífices de innovadores proyectos de inspiración ecológica? ¿Qué hizo a más de un millón de argentinos desechar la moneda y reinstalar el trueque?

Estas preguntas no parecen tener una misma respuesta. Y sin embargo, son inercias que responden a un impulso común. Hoy en el mundo una nueva fuerza (¿iđeológica?, ¿política? ¿espiritual?) se despliega como un proceso silencioso y profundo, como una reacción en cadena frente a la degradación del mundo mercantilizado y deshumanizado. Son las expresiones, minúsculas pero tangibles, de una nueva ciudadanía planetaria, los preludios de una civilización cualitativamente diferente, los esperanzadores cimientos de una «modernidad alternativa». Sus «filosofías políticas» (colocadas bajo el término de «sustentables») no parecen moverse ya dentro de la geometría convencional de izquierdas y derechas, $y$ dado que surgen como experiencias fundamentalmente civiles se hallan por fuera de las complicadas discusiones entre los apóstoles del Estado y los adoradores del mercado. Son, en el fondo, reacciones de la ciudadanía organizada, frente al proceso de globalización perversa que el «sueño neoliberal» pretende imponer por todos los rincones del planeta. Es el renacer de la utopía: la búsqueda y construcción de una sociedad sustentable.

Muy poco se ha documentado de estos nuevos movimientos sociales, y mucho menos se sabe de los resortes que los mueven. A pesar de su enorme heterogeneidad y versatilidad, su principal rasgo es

\footnotetext{
${ }^{1}$ Investigador del Instituto de Ecología de la Universidad Autónoma de México. E-mail: vtoledo@oikos.usam,mx
} 
que son iniciativas realizadas por actores dotados de una cierta «conciencia de especie», de una nueva ética por la solidaridad con los otros seres humanos, con el planeta y con quienes lo habitan. Una conciencia que reconoce tanto los límites de la naturaleza como los abusos cometidos contra ella, y que por lo tanto vive preocupada por la supervivencia de la humanidad y de su entorno. Y es que hoy en día, la sociedad ya no puede ser pensada sin la naturaleza, y la naturaleza ya no puede ser visualizada sin la sociedad. Los tres siglos de industrialización que nos han precedido han subsumido los procesos naturales en los procesos sociales y viceversa.

Hoy, la sociedad global está impactando y desequilibrando varios de los principales ciclos y procesos de la naturaleza, y estamos ya ante lo que U. Beck ha llamado 1a «sociedad del riesgo». Los desusados eventos climáticos de la última década (incluyendo huracanes, inundaciones, sequías e incendios forestales), los impactos de los contaminantes industriales sobre la salud y los alimentos, los agujeros en la atmósfera y los nuevos organismos genéticamente modificados introducidos en la agricultura dan fe de ello. El ensachamiento de la brecha que separa a los sectores y países ricos de los conglomerados marginados y explotados del mundo y la degradación de los más esenciales valores humanos, son otros elementos que contribuyen a incrementar la peligrosidad del mundo actual.

Pero no sólo de ambientalismo se están nutriendo estos nuevos movimientos sociales. Su otra gran fuente de inspiración, explícita o no, proviene de los enclaves menos integrados y modernos del orbe, de las olvidadas reservas civilizatorias de la humanidad: los pueblos indios. Estas culturas indígenas, hablantes de unas 5 mil lenguas diferentes, no sólo conforman la diversidad cultural del género humano, sus territorios se consideran estratégicos porque coinciden con las áreas biológicamente más ricas del planeta. En muchos casos son dueños, además, de enormes extensiones de bosques o selvas, o de las fábricas del agua que, kilómetros abajo, es utilizada en las ciudades y en la industria.

Su principal aporte sin embargo es ideológico y espiritual. Los pueblos indios mantienen una visión del mundo de la que la percepción racionalista y utilitaria que prevalece en los espacios industriales ya no dispone. Para las culturas indígenas la naturaleza no sólo es una respetable fuente productiva, es el centro del universo, el núcleo de la cultura y el origen de la identidad étnica. Y en la esencia de este profundo lazo prevalece la percepción de que todas las cosas, vivas y no vivas, están intrínsecamente ligadas con lo humano. Por lo anterior, cada día un número mayor de pueblos indígenas se lanza a jugar los juegos de la ecología política, y recíprocamente cada vez más contingentes de ambientalistas, conservacionistas y de consumidores verdes, ponen sus esfuerzos en las luchas por la defensa de la cultura, la autogestión comunitaria y los territorios de aquellos. Ecología e indianidad, lejos de ser movimientos reivindicativos dispares, tejen y entretejen los principios de una misma utopía, alimentando de paso la perspectiva de una modernidad diferente.

Y no solo de espiritualidad y de reverencia por la tradición, el recuerdo y el mundo natural, se están alimentando estás nuevas corrientes. También de un nuevo tipo de conocimiento científico, técnico y humanístico, más flexible, menos etéreo y más terrenal, mucho más determinado por las necesidades de la gente, menos condicionado por las élites científicas, o como diría A. Koestler (1981), por los "cavernícolas académicos". Y es que en el fragor de las luchas sociales, un nuevo ejército de científicos (naturales y sociales), técnicos, humanistas, educadores, pedagogos y filósofos han irrumpido, a 
veces con violencia epistemológica, en el actual escenario de los conocimientos. Y son ellos los que están rompiendo el monopolio de la cultura, subvirtiendo los cánones de la ortodoxia teórica y metodológica, atreviéndose a transitar por los nuevos senderos que marca el sentido común, denunciando la corrupción moral de las instituciones y de los científicos al servicio de la guerra y del mercado, ensuciando la actividad reflexiva en los lodos de la construcción alfarera de una nueva utopía. La batalla no es soio epistemológica, también es de política científica y tecnológica, $y$ en fin de proyectos y de instituciones.

Si en 1992, durante la "Cumbre de la Tierra" en Río de Janeiro, el mundo se estremeció con la presencia paralela de cerca de 9,000 organizaciones sociales de 167 países que llevaron hasta las playas de Flamengo a 25,000 militantes buscadores de una "modernidad alternativa" (este impulso logró conectar temporalmente por internet a 17,000 organismos de todo el mundo), diez años después el Foro Social Mundial realizado en Porto Alegre concentró a más de 50,000 participantes de todo el planeta, en la búsqueda de una sociedad diferente, en la construcción de una nueva utopía. Y es que como afirma Tomás R. Villasante, “...tođos los sistemas imperiales o globales que han existido siempre han incubado en su interior experiencias alternativas que les han llevado, antes o después, a otras alternativas de sociedad". 